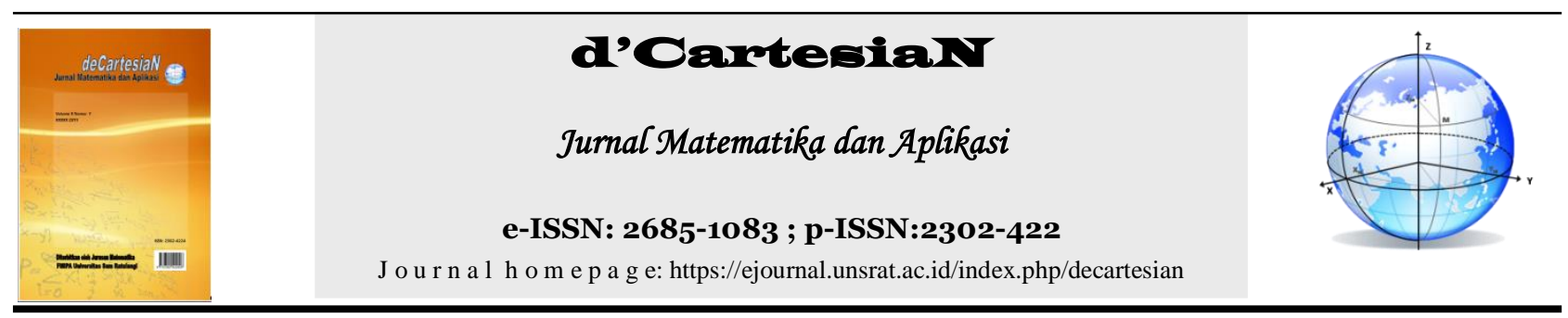

\title{
Analisis Regresi Logistik Untuk Menentukkan Kepuasan Pasien Rawat Inap Pada Kualitas Layanan Rumah Sakit Umum Pusat Prof. Dr. R. D. Kandou Manado
}

\author{
Regina S. Ilham", Marline S. Paendong ${ }^{1}$, John S. Kekenusa ${ }^{{ }^{*}}$ \\ ${ }^{1}$ Jurusan Matematika-Fakultas Matematika dan Ilmu Pengetahuan Alam-Universitas Sam Ratulangi Manado, Indonesia
}

*Corressponding author : johnskekenusa@unsrat.ac.id

\section{A B S T R A K}

Kesehatan merupakan hak asasi sehingga setiap masyarakat berhak memperoleh pelayanan kesehatan secara adil, merata, dan bermutu. Pada masa sekarang ini seiring dengan kemajuan teknologi, rumah sakit yang ada di Indonesia juga ikut berkembang sebagai tempat pelayanan yang memiliki fungsi sebagai pemulihan kesehatan untuk anggota masyarakat, baik secara rawat inap, maupun rawat jalan. Suatu hal yang penting bagi sebuah rumah sakit umum pusat Prof. Dr. R. D. Kandou Manado yang dinilai dari berbagai aspek kualitas layanan yaitu bukti fisik, kehandalan, daya tanggap, jaminan, dan empati. Maka dilakukan penelitian ini untuk menguji pengaruh tingkat kualitas layanan rumah sakit umum pusat Prof. Dr. R. D. Kandou Manado terhadap kepuasan pasien rawat inap. Metode penentuan sampel digunakan adalah propotional sampling sebanyak 100 sampel. Metode analisis yang digunakan adalah analisis regresi logistik biner. Berdasarkan hasil penelitian menggunakan analisis regresi logistik biner maka diperoleh model regresi logistik biner logit $\pi\left(x_{i}\right)=-16,528+0,842 X_{1}-0,306 X_{2}+0,121 X_{3}-$ $0,215 X_{4}+1,108 X_{5}$. Dilihat bahwa aspek layanan yang berpengaruh positif serta signifikan terhadap kepuasan pasien rawat inap adalah variabel tangibles (wujud fisik).

\section{INFO ARTIKEL}

Diterima : 14 Juli 2019

Diterima setelah revisi : 23 Juli 2019

Tersedia online : 25 Juli 2019

\section{Kata Kunci:}

Regresi Logistik Biner

Kepuasan Pasien Rawat Inap

Aspek Layanan

\begin{abstract}
A B S T R A CT
Health is a human right so that every community has the right to receive health services in a fair, equitable and quality manner.At present, along with technological advancements, hospitals in Indonesia also develop as a service place that has a function as a health recovery for community members, both inpatient and outpatient care.An important thing for a central public hospital Prof. Dr. R. D. Kandou Manado which was assessed from various aspects of service, namely tangibles, reliability, responsiveness, assurance, and empathy. So this study was conducted to examine the effect of the level of quality of the services of the central public hospital Prof. Dr. R. D. Kandou Manado towards the satisfaction of hospitalized patients.The method of determining the sample used is proportional sampling of 100 samples.The analytical method used is binary logistic regression analysis. Based on the results of the study using binary logistic regression analysis, the best model of binary logistic regression was obtained $\operatorname{logit} \pi\left(x_{i}\right)=-16,528+$ $0,842 X_{1}-0,306 X_{2}+0,121 X_{3}-0,215 X_{4}+1,108 X_{5}$. From the regression equation, it can be seen that the service aspects that have a positive and significant effect on the satisfaction of inpatients are variable tangibles (physical evidence).
\end{abstract}

\section{INFO ARTIKEL}

Received : 14 July 2019

Received after revision : 23 July 2019

Available online : 25 July 2019

\section{Keywords:}

Binnary Logictic Regression

Inpatient satisfaction

Service aspect

\section{PENDAHULUAN}

Kesehatan merupakan hal yang sangat penting bagi manusia untuk dapat bertahan hidup dan menjalani aktivitas sehari-hari. Kesehatan merupakan hak asasi sehingga setiap masyarakat berhak memperoleh pelayanan kesehatan secara adil, merata, dan bermutu. Sejalannya waktu berbagai upaya dilakukan oleh pemerintah untuk meningkatkan pelayanan kesehatan agar masyarakat mendapatkan pelayanan kesehatan berkualitas.

Rumah sakit adalah tempat untuk melakukan upaya meningkatkan kesehatan, mencegah dan menyembuhkan penyakit, serta memulihkan kesehatan.
Namun, dengan semakin banyaknya jumlah rumah sakit, serta pengguna jasa (pasien) yang semakin selektif dan lebih mengetahui dalam menggunakan fasilitas rumah sakit, hal ini menyebabkan adanya persaingan dalam industri jasa kesehatan yang semakin ketat dan sulit untuk diprediksikan. Dalam kondisi seperti ini dapat menuntut agar rumah sakit selaku salah satu penyedia jasa pelayanan kesehatan untuk dapat meningkatkan kualitas pelayanannya.

Pada masa sekarang ini seiring dengan kemajuan teknologi, rumah sakit yang ada di Indonesia juga ikut berkembang sebagai tempat pelayanan yang memiliki fungsi sebagai pemulihan kesehatan untuk anggota 
masyarakat, baik secara rawat inap, maupun rawat jalan, serta konsultasi pemeliharan atau perawatan kesehatan anggota masyarakat.

Pemerintah mendirikan lembaga kesehatan seperti Puskesmas, Rumah Sakit Umum, dan Rumah Sakit Daerah. Lembaga kesehatan yang sering diakses masyarakat adalah Puskesmas tetapi karena keterbatasan fasilitas yang ada pada Puskesmas, membuat masyarakat memilih rumah sakit umum menjadi rujukan untuk mengakses layanan kesehatan [1].

Rumah Sakit Umum Pusat Prof. Dr. R. D. Kandou Manado juga termasuk rumah sakit yang berkembang. Perkembangan tersebut tentunya menuntut agar pihak rumah sakit dapat meningkatkan kualitas pelayan terhadap pasien. Oleh karena itu, pihak Rumah Sakit Umum Pusat Prof. Dr. R. D. Kandou perlu melakukan analisis untuk menentukan kepuasan pasien dalam upaya meningkatkan proporsi kepuasan pasien. Dalam berbagai ilmu pengetahuan, ilmu statistika semakin menunjukan perannya dalam memberikan solusi analisis yang mendalam. Salah satu diantaranya analisis regresi logistik biner.

Regresi Logistik Biner adalah bentuk regresi yang digunakan untuk memodelkan hubungan variabel dependen dan variabel independen sebuah data dengan ukuran biner/dikotomi (misal : ya atau tidak, sukses atau gagal, puas atau tidak puas) maka regresi logistik tersebut menggunakan regresi logistik biner.

Metode analisis tersebut karena sebagaimana dipahami bahwa kepuasan pengunjung atau pasien merupakan peristiwa dikotomi atau biner yang hanya memiliki dua kategori yaitu kategori yang menyatakan kejadian seperti sukses atau gagal, puas atau tidak puas, maka regresi logistik biner adalah metode analisis yang tepat digunakan dalam kasus penelitian ini. Dibandingkan dengan metode analisis regresi lainnya yang secara umum digunakan untuk mencari pola hubungan antara dua variabel atau lebih, sedangkan regresi logistik biner khusus digunakan untuk mencari pola hubungan antara dua variabel yang bersifat biner.

Dalam penelitian ini kualitas layanan akan menjadi pusat perhatian atau sebagai variabel karena berhubungan langsung dengan kepuasan pasien. Adapun kualitas layanan yang dimaksud adalah bukti fisik (tangibles), kehandalan (reliability), daya tanggap (responsiveness), jaminan (assurance), dan empati (emphaty). Dimensi inilah yang akan mempengaruhi kepuasan pengunjung pada rumah sakit umum Prof. Dr. R. D. Kandou.

Analisis Regresi Logistik Biner juga pernah diteliti oleh Tampil dkk (2017), dengan judul Analisis Regresi Logistik untuk menentukan faktor-faktor yang mempengaruhi Indeks Prestasi Kumulatif (IPK) mahasiswa FMIPA Universitas Sam Ratulangi [2].

\section{Analisis Regresi}

Analisis regresi merupakan salah satu analisis dalam statistik yang digunakan untuk menaksir pola hubungan sebab-akibat antara variabel bebas (independen) dan variabel terikat (dependen). Variabel dependen yang biasanya disimbolkan sebagai (y) adalah variabel yang nilainya ditentukan oleh variabel lain, sedangkan variabel independen yang biasanya di simbolkan sebagai (x) adalah variabel yang nilainya dapat ditentukan secara bebas berdasarkan dugaan bahwa variabel tersebut memiliki pengaruh terhadap variabel dependen. Bentuk umum persamaan analisis regresi adalah sebagai berikut.

$$
Y_{i}=\beta_{0}+\beta_{1} X_{i}+\varepsilon_{i}
$$

Dimana :

$Y_{i}=$ Variabel terikat untuk pengamatan $\mathrm{ke}-\mathrm{i}$

$\beta_{0}=$ Nilai konstanta

$\beta_{1}=$ Parameter model

$X_{i}=$ Variabel bebas pengamatan ke $-\mathrm{i}$

$\varepsilon_{i}=$ Galat regresi

Salah satu regresi nonlinier yang dapat digunakan untuk menganalisis data kualitatif adalah model regresi logistik [3].

\section{Regresi Logistik}

Regresi logistik merupakan bagian dari modelmodel statistika yang disebut model linier yang digeneralisasi. Dari variabel independen regresi logistik terbagi menjadi dua yaitu regresi logistik sederhana (hanya memiliki satu variabel independen) dan regresi logistik berganda (memiliki lebih dari satu variabel independen) sedangkan jika dilihat dari variabel dependennya regresi dibagi menjadi dua yaitu regresi logistik biner (variabel dependennya dichotomous atau hanya memiliki dua kategori) dan regresi logistik multinomial (variabel dependennya memiliki lebih dari dua kategori atau polytomous) [4].

\section{Analisis Regresi Logistik Biner}

Pada regresi logistik jika variabel terikatnya terdiri dari dua kategori misalnya $\mathrm{Y}=1$ menyatakan hasil yang diperoleh "sukses" dan Y=o menyatakan hasil yang diperoleh "gagal" maka regresi logisitk tersebut menggunakan regresi logistik biner. Variabel (y) yang demikian lebih tepat dikatakan sebagai variabel indikator dan memenuhi distribusi Bernoulli. Fungsi probabilitasdistribusi Bernoulli, yaitu:

$$
\begin{gathered}
f\left(y_{i} ; \pi_{i}\right)=\left\{\begin{array}{cc}
\pi_{i} 1-\pi_{i^{1-y_{i}}} \text { untuk } y_{i}=0,1 \\
0 & \text { untuk } y_{i} \text { yang lain }
\end{array}\right. \\
V(Y)=E\left(Y^{2}\right)-[E(Y)]=\pi(x)[1-\pi(x)]
\end{gathered}
$$

Secara umum model probabilitas regresi logistik dengan melibatkan beberapa variabel independen $\mathrm{x}$ dapat diformulasikan sebagai berikut:

$$
\pi\left(x_{i}\right)=\frac{e^{\beta_{0}+\beta_{1} X_{1}+\beta_{2} X_{2}+\cdots+\beta_{k} X_{k}}}{1+e^{\beta_{0}+\beta_{1} X_{1}+\beta_{2} X_{2}+\cdots+\beta_{k} X_{k}}}
$$

Dimana $\mathrm{k}$ adalah banyaknya variabel independen dan $\pi\left(x_{i}\right)$ merupakan peluang terjadinya kejadian puas dan tidak puas. Fungsi $\pi(x)$ merupakan fungsi non linear sehingga perlu dilakukan transformasi logit untuk memperoleh fungsi yang linear agar dapat dilihat hubungan antara variabel dependen (y) dengan variabel independen ( $\mathrm{x}$ ). Model logit dari $\pi(\mathrm{x})$ dinyatakan sebagai $\mathrm{g}(\mathrm{x})$, yaitu:

$$
g(x)=\ln \frac{\pi(x)}{1-\pi(x)}
$$

Model umum regresi logistik setelah disubtitusikan dengan model logit dari $\pi(\mathrm{x})$ diperoleh:

$$
\text { logit } \pi\left(x_{i}\right)=\beta_{0}+\beta_{1} X_{1}+\beta_{2} X_{2}+\cdots \beta_{k} X_{k}
$$

Dalam regresi logistik terdapat beberapa perbedaan dengan regresi pada umumnya yaitu regresi logistik tidak mengasumsikan suatu hubungan yang linear antara variabel independen dengan variabel dependen, tidak memerlukan asumsi multivariate normality pada variabel independennya, tidak ada asumsi homokedastisitas, variabel independen tidak perlu diubah ke dalam bentuk metrik (interval atau skala ratio), variabel dependen harus bersifat dikotomi (2 kategori, contoh: tinggi dan rendah atau puas dan tidak puas), tidak adanya multikolinearitas, kategori dalam 


\section{Analisis Regresi Logistik untuk Menentukan Kepuasan Pasien Rawat inap pada Kualitas Layanan Rumah Sakit Umum Pusat Prof. Dr. R. D. Kandou Manado \\ d'Cartesian : Jurnal Matematika dan Aplikasi, Vol. 8 No. 2 (September 2019): 147-152}

variabel independen harus terpisah satu samalain atau bersifat eksklusif, dan sampel yang diperlukan dalam jumlah relatif besar, minimum dibutuhkan hingga 50 sampel [5].

\section{Uji Simultan}

Uji Simultan (serentak) dilakukan untuk mengetahui signifikn parameter $\beta$ terhadap variabel dependen secara keseluruhan. Pengujian parameter model secara serentak menggunakan uji rasio kemungkinan (ratio likelihood test) dengan menggunakan statistik uji G yang digunakan untuk menguji peranan variabel independen didalam model secara bersama- sama dengan rumus sebagai berikut :

$$
G=-2 \ln \frac{L_{o}}{L_{p}}
$$

Hipotesis dari persamaan di atas adalah $H_{0}: \beta_{1}=$ $\beta_{2}=\cdots \beta_{P}=0$ ( Tidak ada pengaruh antara variabel independen terhadap variabel dependen).

$H_{1}$ : Minimal terdapat satu $\beta_{j} \neq 0$. Dengan $\mathrm{j}=1,2, \ldots \mathrm{p}$ (Ada pengaruh antara variabel independen terhadap variabel dependen).

Kriteria ini mengambil taraf nyata $\alpha=$ 0,05 maka $H_{0}$ di terima jika $G<X_{(a, v)}^{2}$ dan $H_{0}$ ditolak jika $G \geq X_{(a, v)}^{2}$.

\section{Uji Parsial}

Pengujian parameter secara parsial (individu) menggunakan uji wald, hasil pengujian secara parsial akan menunjukkan apakah suatu variabel independen layak untuk masuk dalam model atau tidak.

Hipotesis yang akan diuji adalah :

$H_{0}: \beta_{j}=0$ Dengan $\mathrm{j}=1,2, \ldots \mathrm{p}$ ( Tidak ada pengaruh antara masing-masing variabel independen terhadap variabel dependen).

$H_{1}: \beta_{j} \neq 0$. Dengan $\mathrm{j}=1,2, \ldots \mathrm{p}$ (Ada pengaruh antara masing-masing variabel independen terhadap variabel dependen).

Statistik uji Wald didefinisikan sebagai :

$$
W=\frac{\widehat{\beta}_{i}}{S E\left(\widehat{\beta}_{i}\right)}
$$

dan

$$
S E\left(\hat{\beta}_{i}\right)=\sqrt{\left(\sigma^{2}\left(\beta_{i}\right)\right)}
$$

Dimana :

$S E\left(\hat{\beta}_{i}\right)=$ dugaan galat baku untuk koefisien $\hat{\beta}_{i}$

$\hat{\beta}_{i}=$ nilai dugaan untuk parameter $\left(\hat{\beta}_{i}\right)$

Kriteria penolakan (tolak $H_{0}$ ) jika nilai $\mathrm{W}>Z_{\alpha / 2}$ atau $\mathrm{p}$ - value $<\alpha[6]$.

\section{Uji Kecocokan Model}

Uji kecocokan model digunakan untuk mengevaluasi cocok tidaknya model dengan data, nilai observasi yang diperoleh sama atau mendekati dengan yang diharapkan dalam model. Model yang digunakan harus layak atau memenuhi Goodness of Fit (GoF). Suatu model dikategorikan memenuhi $G o F$ jika terdapat kesesuaian antara data yang dimasukkan dalam model dengan data yang diamati. Dalam regresi logistik metode untuk menguji kelayakan model diukur dengan nilai chisquare dengan uji Homser and Lemeshow. Pengujian ini dengan melihat nilai goodness of fit test yang diukur dengan nilai chi-square pada tingkat signifikan $5 \%$ [7].
Keputusan penerimaan hipotesis didasarkan pada pertimbangan sebagaiberikut: $H_{0}=$ model yang dihipotesiskan fit dengan data

$H_{1}=$ model yang dihipotesiskan tidak fit dengan data

Untuk menguji hipotesis digunakan model Hosmer and Lemeshow's Goodness of Fit test, jika nilai Hosmer and Lemeshow's Goodness of Fit test statistik sama dengan atau kurang dari 0,05. Artinya, hipotesis nol ditolak yang berarti ada perbedaan signifikansi antara model dengan nilai observasinya, yang Goodness of fit model tidak baik karena model tidak dapat memprediksi nilai observasinya. Jika nilai Hosmer and Lemeshow's Goodness of Fit test lebih besar dari 0,05. Artinya, hipotesis nol tidak dapat ditolak dan berarti model mampu memprediksi nilai observasinya atau dapat dikatakan model dapat ditemui karena cocok dengan observasinya. [8]

Statistik uji Hosmer and Lemeshow di formulasikan sebagai berikut:

$\hat{C}=\sum_{r=1}^{g} \frac{\left(O_{r}-n^{\prime} r \hat{p}_{1 r}\right)^{2}}{n^{\prime} r \hat{p}_{1 r}\left(1-\hat{p}_{1 r}\right)} \quad(\mathrm{r}=1,2, \ldots, \mathrm{g})$

Dengan :

$g=$ banyaknya grup

$n^{\prime} r=$ jumlah observasi dalam grup ke $\mathrm{r}$

$O_{r}=$ jumlah nilai Y pada grup ke $\mathrm{r}$

$\hat{p}_{1 r}=$ rata-rata taksiran probabilitas sukses grup ke $\mathrm{r}$

Statistik $\hat{C}$ mengikuti sebaran $X^{2}$ dengan membandingkan nilai chi-square yang diperoleh dengan nilai chi-square pada tabel chi-square dengan derajat bebas $\mathrm{df}=\mathrm{g}-2$, dimana $\mathrm{g}$ adalah banyaknya kelompok pengamatan. Kriteria keputusan $H_{0}$ ditolak jika $\hat{C}>$ $X_{(a, g-2)}^{2}[9]$.

\section{METODE PENELITIAN}

Penelitian ini dilaksanakan selama bulan Desember 2018 sampai Mei 2019, bertempat di Rumah Sakit Umum Pusat Prof. Dr. R. D. Kandou Manado. Pengolahan data dilakukan di Laboratorium Statistika Jurusan Matematika, FMIPA Unsrat.

Populasi dalam penelitian ini adalah pasien rawat inap di Rumah Sakit Umum Pusat Prof. Dr. R. D. Kandou Manado pada bulan Maret 2019 sebanyak 6.992 pasien Sehingga akan dicari sampel pada ruangan Irena A, B, C, D, E, F, Anggrek 1 dan Anggrek 2 yang ada pada batasan masalah dengan menggunakan rumus slovin sebagai berikut :

$$
n=\frac{N}{N d^{2}+1}
$$

Dimana :

$\mathrm{n}=$ jumlah sampel

$\mathrm{N}=$ jumlah populasi

$d=$ presisi yang ditetapkan (10\%) [10].

maka :

$$
n=\frac{6.992}{6.992 \times(0,1)^{2}+1}=98,589 \cong 99
$$

Setelah dihitung menggunakan rumus slovin didapat jumlah sampel 99 agar lebih akurat maka dalam penelitian ini diambil 100 sampel, setelah mendapat jumlah sampel maka dilakukan penarikan sampel berdasarkan propotional sampling, setelah dilakukan penarikan sampel diperoleh sampel sebagai berikut: 
Tabel 1. Data pengambilan sampel pada ruangan

\begin{tabular}{cc}
\hline Ruangan & Jumlah sampel \\
\hline Irena A & 20 \\
Irena B & 15 \\
Irena C & 15 \\
Irena D & 10 \\
Irena E & 10 \\
Irrna F & 10 \\
Anggrek 1 & 10 \\
Anggrek 2 & 10 \\
\hline
\end{tabular}

Langkah-langkah dalam menganalisis data adalah sebagai berikut :

1. Uji validitas dan reliabilitas

2. Melakukan uji signifikansi parameter secara simultan dengan menggunakan statistik uji G untuk mengetahui apakah variabel independen secara bersama-sama berpengaruh terhadap model.

3. Melakukan uji signifikansi paramaeter secara parsial dengan menggunakan statistik uji Wald untuk mengetahui koefisien paramater yang berpengaruh secara individual terhadap model.

4. Melakukan uji statistika dengan menggunakan analisis regresi logistik biner dengan model umum sebagai berikut:

Logit $\pi\left(x_{i}\right)=\frac{e^{\beta_{0}+\beta_{1} X_{1}+\beta_{2} X_{2}+\cdots+\beta_{k} X_{k}}}{1+e^{\beta_{0}+\beta_{1} X_{1}+\beta_{2} X_{2}+\cdots+\beta_{k} X_{k}}}$

5. Melakukan uji kecocokan model regresi logistic biner diukur dengan nilai chi-square dan uji Hosmer and Lemeshow dengan melihat nilai goodness of fit test yang diukur dengan nilai chi-square pada tingkat signifikan $5 \%$ dengan hipotesis.

6. Membuat kesimpulan.

\section{HASIL DAN PEMBAHASAN}

\section{Karakteristik Responden}

Dari Kuesioner yang terkumpul diperoleh data pasien adalah seperti pada tabel 2.

Tabel 2. Deskrifptif Responden

\begin{tabular}{|c|c|c|c|c|c|}
\hline \multirow{2}{*}{ No } & \multirow{2}{*}{ Usia } & \multicolumn{2}{|c|}{$\begin{array}{c}\text { Jenis } \\
\text { Kelamin }\end{array}$} & \multirow{2}{*}{ Jumlah } & \multirow{2}{*}{ Persentase } \\
\hline & & $\mathrm{L}$ & $P$ & & \\
\hline 1 & $\leq 20$ & 4 & o & 4 & $4 \%$ \\
\hline 2 & $\begin{array}{l}21- \\
30\end{array}$ & 7 & 5 & 12 & $12 \%$ \\
\hline 3 & $\begin{array}{l}31- \\
40\end{array}$ & 6 & 7 & 13 & $13 \%$ \\
\hline 4 & $\begin{array}{l}41^{-} \\
50\end{array}$ & 6 & 11 & 17 & $17 \%$ \\
\hline 5 & $>50$ & 34 & 20 & 54 & $54 \%$ \\
\hline \multicolumn{2}{|c|}{ Jumlah } & 56 & 44 & 100 & $100 \%$ \\
\hline \multicolumn{2}{|c|}{ Persentase } & $56 \%$ & $44 \%$ & $100 \%$ & \\
\hline
\end{tabular}

Data jumlah pasien rawat inap di rumah sakit umum pusat Prof. Dr. R. D. Kandou Manado pada bulan Januari 2018 - April 2019 berdasarkan jenis kelamin sebagai berikut :
Tabel 3. Data Pasien Rawat Inap Rumah Sakit Prof. Dr. R. D. Kandou Manado

\begin{tabular}{|c|c|c|c|}
\hline \multirow{2}{*}{ Bulan } & \multicolumn{2}{|c|}{ Jenis Kelamin } & \multirow{2}{*}{ Jumlah Pasien } \\
\hline & $\mathrm{L}$ & $\mathrm{P}$ & \\
\hline Jan-18 & 3.628 & 3.362 & 6.990 \\
\hline Feb-18 & 3.473 & 2.820 & 6.293 \\
\hline Mar-18 & 3.561 & 3.256 & 6.817 \\
\hline Apr-18 & $3 \cdot 374$ & 3.204 & 6.578 \\
\hline Mei-18 & $3 \cdot 317$ & 3.024 & 6.341 \\
\hline Jun-18 & 3.216 & 2.742 & 5.958 \\
\hline Jul-18 & 3.235 & 3.006 & 6.241 \\
\hline Agust-18 & 3.378 & 2.900 & 6.278 \\
\hline Sep-18 & 3.199 & 2.845 & 6.044 \\
\hline Okt-18 & 3.603 & $3 \cdot 387$ & 6.990 \\
\hline Nop-18 & 3.477 & 3.149 & 6.626 \\
\hline Des-18 & 3.463 & 3.109 & 6.572 \\
\hline Jan-19 & 4.387 & 3.803 & 8.190 \\
\hline Feb-19 & 3.598 & $3 \cdot 340$ & 6.938 \\
\hline Mar-19 & 3.625 & 3.367 & 6.992 \\
\hline Apr-19 & $3 \cdot 351$ & 3.122 & 6.473 \\
\hline Total & 55.885 & 50.436 & 106.321 \\
\hline
\end{tabular}

\section{Uji Validitas dan Reliabiltas}

Sebelum dianalisis diuji validitas dan reliabilitas. Korelasi antara tiap pertanyaan dengan total jawaban sebagai berikut :

Tabel 4. Uji Validitas

\begin{tabular}{|c|c|c|c|c|c|c|}
\hline & $p_{1}$ & $p_{2}$ & $p_{3}$ & $p_{4}$ & $p_{5}$ & $p_{6}$ \\
\hline$X_{1}$ & 0,728 & 0,650 & 0,675 & 0,728 & 0,708 & 0,592 \\
\hline $\mathrm{P}$ & 0,000 & 0,000 & 0,000 & 0,000 & 0,000 & 0,000 \\
\hline$X_{2}$ & 0,629 & 0,603 & 0,655 & 0,700 & 0,444 & 0,722 \\
\hline $\mathrm{P}$ & 0,000 & 0,000 & 0,000 & 0,000 & 0,000 & 0,000 \\
\hline$X_{3}$ & 0,844 & 0,825 & 0,824 & 0,811 & & \\
\hline $\mathrm{P}$ & 0,000 & 0,000 & 0,000 & 0,000 & & \\
\hline$X_{4}$ & 0,806 & 0,731 & 0,843 & 0,857 & 0,840 & \\
\hline $\mathrm{P}$ & 0,000 & 0,000 & 0,000 & 0,000 & 0,000 & \\
\hline$X_{4}$ & 0,896 & 0,853 & & & & \\
\hline $\mathrm{P}$ & 0,000 & 0,000 & & & & \\
\hline
\end{tabular}

Tabel 4 menunjukkan bahwa hasil uji validitas adalah valid karena nilai $\mathrm{P}$ atau tabel pearson $<0,05$. Penjelasan pada tabel adalah dimana $\mathrm{p}$ adalah pertanyaan pada kuesioner, $\mathrm{X}$ adalah variabel. Misalnya pada variabel $X_{1}$ ada 6 pertanyaan dst.

Tabel 5. Hasil Uji Reliabilitas

\begin{tabular}{lccccc}
\hline & $X_{1}$ & $X_{2}$ & $X_{3}$ & $X_{4}$ & $X_{5}$ \\
\hline $\begin{array}{l}\text { Cronbach's } \\
\text { Alpha }\end{array}$ & 0,769 & 0,740 & 0,823 & 0,809 & 0,879 \\
& & & & & \\
\hline
\end{tabular}

Tabel 5 dapat disimpulkan bahwa ternyata hasil uji reliabilitas dengan uji cronbach's alpha adalah reliable.

\section{Uji Signifikan Parameter}

a. Uji Simultan

Uji simultan dilakukan untuk mengetahui signifikan parameter terhadap model secara serentak.

Untuk melihat data, dapat dilihat pada tabel dibawah ini :

Tabel 6. Model Ringkasan

\begin{tabular}{rrr}
-2 Log likelihood & Cox \& Snell R Square & \multicolumn{2}{c}{ Nagelkerke R Square } \\
\hline $27,363^{\text {a }}$ &, 116 &, 354 \\
\hline
\end{tabular}

Hasil pada tabel 6 diperoleh nilai rasio kemungkinan sebesar 27,363. Nilai pada Chi-square 


\section{Analisis Regresi Logistik untuk Menentukan Kepuasan Pasien Rawat inap pada Kualitas Layanan Rumah Sakit Umum Pusat Prof. Dr. R. D. Kandou Manado \\ d'Cartesian : Jurnal Matematika dan Aplikasi, Vol. 8 No. 2 (September 2019): 147-152}

tabel $=9,48$ dengan $\alpha=0,05$ dan $\mathrm{df}=4$, dengan demikian dapat dilihat bahwa $G \geq X_{(a, v)}^{2}$ yaitu 27,363 $\geq$ 9,48 sehingga $H_{0}$ ditolak, itu berarti bahwa paling sedikit ada satu variabel independen yang berpengaruh secara simultan terhadap variabel dependen pada $\alpha=0,05$. Tabel diatas menunjukkan bahwa koefisien determinan $\left(R^{2}\right)$ regresi logistik sebesar 0,354 sehingga dikatakan kontribusi variabel independen terhadap variabel dependen adalah sebesar 35,4\%.

Pada tabel 7 dapat dilihat bahwa ketetapan prediksi dalam penelitian ini adalah sebesar $96 \%$. Berdasarkan nilai prediksi yang diperoleh pada tabel diatas kepuasan pasien yaitu 99 orang puas terhadap layanan rumah sakit, baris observasi diprediksi oleh model 4 orang tidak puas dalam pelayanan rumah sakit dan 95 orang puas dalam pelayanan rumah sakit. Nilai prediksi kepuasan pasien yaitu 1 orang tidak puas terhadap layanan rumah sakit dan 99 orang puas terhadap layanan rumah sakit.

Tabel 7. Klasifikasi prediksi dan observasi kepuasan pasien

Observed Predicted

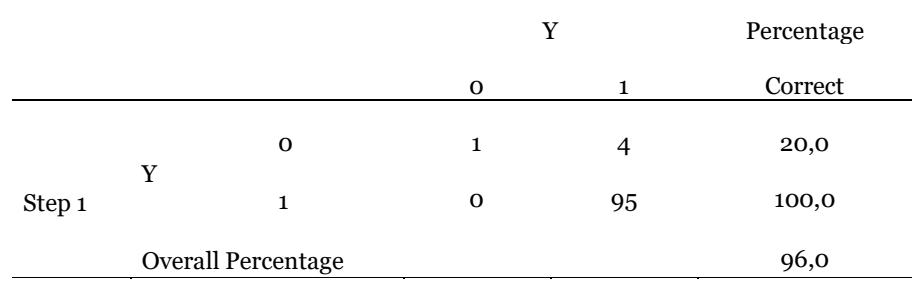

$H_{0}$ ditolak apabila nilai signifikan pada statistik $<\alpha=0,05$ Pada tabel 8 Dapat dilihat bahwa didapatkan nilai signifikan sebesar o,030 dimana lebih kecil dari nilai $\alpha=0,05$ dengan kesimpulan $H_{0}$ ditolak yang berarti minimal ada satu variabel bebas yang secara bersama-sama mempengaruhi model.

Tabel 8. Omnibus dari Model Koefisien

\begin{tabular}{|c|c|c|c|c|}
\hline & & Chi-square & Df & Sig. \\
\hline \multirow{3}{*}{ Step 1} & Step & 12,340 & 5 & ,030 \\
\hline & Block & 12,340 & 5 & ,030 \\
\hline & Model & 12,340 & 5 & ,030 \\
\hline
\end{tabular}

b. Uji Parsial

Uji Parsial (individu) dilakukan untuk mengetahui keberartian parameter terhadap model.

\begin{tabular}{|c|c|c|c|}
\hline \multicolumn{4}{|c|}{ Tabel 9. Uji Parsial } \\
\hline & Nald & Df & Sig \\
\hline & & 1 & \\
\hline $\mathrm{X} 1$ & 4,232 & & ,040 \\
\hline & & 1 & \\
\hline $\mathrm{X} 2$ & ,465 & & 495, \\
\hline & & 1 & \\
\hline $\mathrm{X}_{3}$ & ,096 & & ,756 \\
\hline & & 1 & \\
\hline $\mathrm{X}_{4}$ & ,220 & & ,639 \\
\hline & & 1 & \\
\hline $\mathrm{X}_{5}$ & 2,603 & & 107, \\
\hline
\end{tabular}

Dengan $\alpha=0,05$ dan $d f=1$ pada tabel chi-square diperoleh nilai chi-square tabel $=3,841$. Dari hasil uji statistik wald diatas, nilai uji statistik pada variabel $X_{1}$ lebih besar dari nilai chi-square tabel, sedangkan nilai variabel $X_{2}, X_{3}, X_{4}, X_{5}$ lebih kecil dari nilai chi-square tabel.

\section{Uji Kecocokan Model}

Uji Kecocokan Model dilakukan untuk mengevaluasi cocok tidaknya model dengan data dan memenuhi Goodness of Fit (GOF).

Dilihat pada tabel 5, diperoleh statistik uji chisquare untuk uji kecocokan Hosmer and Lemeshow seperti pada tabel 10 sebagai berikut :

Tabel 10. Hosmer and Lemeshow Test

\begin{tabular}{lcccc} 
Step & Chi-square & Df & \multicolumn{1}{c}{ Sig. } \\
\hline 1 & 9,079 & & 8 &, 336 \\
\hline
\end{tabular}

Nilai chi-square tabel $=15,51$ dengan $\alpha=0,05$ dan $d f(g-2)=8$, dengan demikian dapat dilihat bahwa, $\hat{C}<$ $X_{(a, g-2)}^{2}$ yaitu $9,079<15,51$. Hasil pengujian statistik menunjukan probabilitas signifikansi diperoleh angka o,336 dimana lebih besar dari nilai $\alpha=0,05$, sehingga dapat disimpulkan $H_{0}$ diterima jika yang berarti tidak ada perbedaan antara observesi dan prediksi dengan kata lain model fit atau layak untuk digunakan .

\section{Model Regresi Logistik Biner}

Berdasarkan analisis data yang telah dilakukan dengan regresi logistik biner sesuai.

Tabel 11. Nilai Koefisien Variabel

\begin{tabular}{cccc}
\hline Variabel & B & SE & Sig \\
\hline$X_{1}$ &, 842 &, 409 &, 040 \\
$X_{2}$ &,- 306 &, 448 &, 495 \\
$X_{3}$ &, 121 &, 389 &, 756 \\
$X_{4}$ &,- 215 &, 458 &, 639 \\
$X_{5}$ & 1,108 &, 687 &, 107 \\
Constant & $-16,528$ & 8,943 &, 065 \\
\hline
\end{tabular}

$\operatorname{logit} \pi\left(x_{i}\right)=-16,528+0,842 X_{1}-0,306 X_{2}+0,121 X_{3}$

$$
-0,215 X_{4}+1,108 X_{5}
$$

\section{Interpretasi Model Regresi Logistik Biner}

Berdasarkan hasil analisis secara parsial diatas diperoleh nilai-nilai estimasi parameter untuk persamaaan regresi logistik biner. Pada persamaan diatas memiliki nilai konstan $-16,528$. Selain itu, dari persamaan dapat dilihat besar masing-masing koefisien variabel independen dari persamaan tersebut, maka hasil interpretasi nilai koefisien variabel, yaitu :

a. Nilai koefisien regresi 0,842 pada variabel tangibles $\left(X_{1}\right)$ berpengaruh secara positif dan signifikan terhadap kepuasan pasien $(\mathrm{Y})$ dalam pelayanan rumah sakit. Hal ini dapat ditunjukkan pada tabel 11, dengan nilai signifikan sebesar 0,040 yang lebih kecil dari nilai $\alpha=0,05$. Dapat disimpulkan bahwa semakin tinggi variabel tangibles $\left(X_{1}\right)$ yang diberikan rumah sakit kepada pasien, maka akan semakin tinggi pula kepuasan pasien.

b. Nilai koefisien regresi $-0,306$ pada variabel reliability $\left(X_{2}\right)$ tidak berpengaruh dan tidak signifikan terhadap kepuasan pasien $(\mathrm{Y})$ dalam pelayanan rumah sakit. Hal ini dapat ditunjukkan pada tabel 11, dengan nilai signifikan 
sebesar 0,495 yang jauh lebih besar dari nilai nilai $\alpha=0,05$ ditambah nilai koefisien variabel reliability $\left(X_{2}\right)$ bernilai negatif.

c. Nilai koefisien regresi 0,121 pada variabel responsivenes $\left(X_{3}\right)$, berpengaruh secara positif terhadap kepuasan pasien $(\mathrm{Y})$ dalam pelayanan rumah sakit, akan tetapi tidak signifikan. Hal ini dapat ditunjukkan pada tabel 11 dengan nilai signifikan sebesar 0,756 yang jauh lebih besar dari nilai nilai $\alpha=0,05$. Dapat disimpulkan bahwa variabel responsivenes $\left(X_{3}\right)$, berpengaruh secara positif tapi tidak signifikan terhadap kepuasan pasien.

d. Nilai koefisien regresi $-0,215$ pada variabel assurance $\left(X_{4}\right)$, tidak berpengaruh dan tidak signifikan terhadap kepuasan pasien $(\mathrm{Y})$ dalam pelayanan rumah sakit. Hal ini dapat ditunjukkan pada tabel 11 dengan nilai signifikan o,639 yang jauh lebih besar dari nilai $\alpha=$ 0,05 ditambah nilai koefisien variabel assurance $\left(X_{4}\right)$ bernilai negatif.

e. Nilai koefiisien regresi 1,108 pada variabel empathy $\left(X_{5}\right)$ berpengaruh secara positif akan tetapi tidak signifikan terhadap kepuasan pasien (Y) dalam pelayanan rumah sakit, hal ini dapat ditunjukkan pada tabel 11 dengan nilai signifikan sebesar 0,107 yang lebih besar dari nilai $\alpha=0,05$ dapat disimpulkan bahwa variabel empathy $\left(X_{5}\right)$, berpengaruh secara positif tapi tidak signifikan terhadap kepuasan pasien.

\section{PENUTUP}

\section{Kesimpulan}

1. Model persamaan Logistik Biner terhadap pengaruh kualitas layanan di Rumah Sakit Umum Pusat Prof. Dr. R. D. Kandou Manado terhadap kepuasan pasien rawat inap :

$$
\begin{gathered}
\operatorname{logit} \pi\left(x_{i}\right)=-16,528+0,842 X_{1}-0,306 X_{2}+ \\
0,121 X_{3}-0,215 X_{4}+1,108 X_{5}
\end{gathered}
$$

2. Berdasarkan hasil yang telah diuji diketahui aspek yang berpengaruh terhadap kepuasan pasien rawat inap pada layanan rumah sakit adalah wujud fisik karena bersifat positif.

\section{Saran}

Sangat diharapkan untuk pelayanan Rumah Sakit Umum Pusat Prof. Dr. R. D. Kandou Manado agar tetap konsisten dalam melayani dan lebih meningkatkan kualitas pelayanan terhadap pasien.

\section{REFERENSI}

[1] Moenir, H. A. S. 2006. Manajemen Pelayanan Umum di Indonesia. PT. Bumi Aksara. Jakarta

[2] Tampil, Y. A., H. Komalig., dan Y. Langi. 2017. Analisis Regresi Logistik untuk Menentukan faktorfaktor yang Mempengaruhi Indeks Prestasi Kumulatif (IPK) Mahasiswa Universitas Sam Ratulangi Manado. Jurnal Decartesian 6(2) : 5-7

[3] Aisyah, N. 2010. Regresi Logistik dan Penerapannya dalam Bidang Kesehatan. Universitas Islam Negeri Sunan Kalijaga. Yogyakarta

[4] Albana, M. 2009. Aplikasi Regresi Logistik Ordinal
Untuk Menganalisis Tingkat Kepuasan Pengguna Jasa terhadap Pelayanan di Stadiun Kota Jakarta. Skripsi. Universitas Pakuan. Bogor

[5] Sabri, L., dan H. S. Sutanto. 2006. Statistik Kesehatan. PT. Raja Grafindo Persada. Jakarta

[6] Hosmer, D. W., and Lemeshow. 2000. Aplied Logistic Regression. John Wiley and Son. New York

[7] Utomo, S. 2014. Model Regresi Logistik Untuk Menunjukkan pengaruh Pendapatan Per kapita, Tingkat Pendidikan, dan Status Pekerjaan terhdap Status Gizi Masyarakat. Skripsi. Universitas Sebelas Maret. Surakarta

[8] Atmawati, R., dan Wahyuddin. 2003. Analisis Pengaruh Kualitas Pelayanan terhadap Kepuasan Konsumen pada Matahari Departemant Store Solo Grand Mall. Jurnal Pasca Sarjana Universitas Muhammadiya. Surakarta

[9] Handayani, R. 2014. Penerapan Regresi Logistik dalam Menganalisis Adopsi Teknologi Pertanian. Jurnal Penelitian Pengkajian dan Pengembangan Teknologi. Semarang

[10] Riduwan dan Akdon. 2007. Rumus dan Data dalam Analisis Statistik. Alfabeta. Bandung

\section{Regina Serafin Ilham (reginaserafin97@gmail.com)}

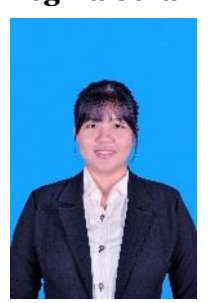

Lahir di Manado, pada tanggal 14 Oktober 1997. Menempuh pendidikan tinggi Jurusan Matematika, FMIPA, Universitas Sam Ratulangi Manado. Tahun 2019 adalah tahun terakhir ia menempuh studi. Makalah ini merupakan hasil penelitian skripsinya yang dipublikasikan.

John S. Kekenusa (johnskekenusa@unsrat.ac.id)

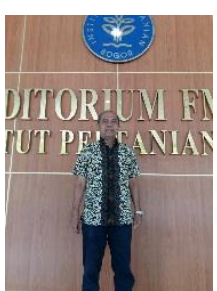
Lahir di Tahuna, Sulawesi Utara pada tanggal 24 Agustus 1958. Pada tahun 1982 mendapatkan gelar Sarjana yang diperoleh dari Fakultas Perikanan Universitas Sam Ratulangi Manado. Pada tahun 1988 mendapatkan gelar Magister Statistika Terapan di Institut Pertanian Bogor, dan pada tahun 2006 mendapat gelar Doktor yang diperoleh dari MIPA, UNAIR Surabaya. Jabatan Akademik Profesor (Guru Besar, Statistika) sejak tahun 2007.

Marline S. Paendong (Marline paendong@yahoo.com) Pada tahun 1999, memperoleh gelar sarjana di Program Studi Matematika, Universitas Gadjah Mada. Gelar Sarjana Sains (S.Si) diperoleh dari Universitas Gadjah Mada pada tahun 2006. Gelar Magister Sains diperoleh di Institut Pertanian Bogor pada tahun 2006. Ia bekerja di UNSRAT di Program Studi Matematika sebagai pengajar akademik tetap dan bekerja di Kantor Rektor UNSRAT sebagai Lektor. 